\title{
Tunable tribological properties in water-based lubrication of water-soluble fullerene derivatives via varying terminal groups
}

\author{
LIU YuHong $^{1 *}$, LIU PengXiao ${ }^{1}, \mathrm{CHE} \mathrm{Lu}^{1}$, SHU ChunYing $^{2} \&$ LU XinChun $^{1}$ \\ ${ }^{1}$ State Key Laboratory of Tribology, Tsinghua University, Beijing 100084, China; \\ ${ }^{2}$ Key Laboratory of Molecular Nanostructure and Nanotechnology, Institute of Chemistry, Chinese Academy of Sciences, Beijing 100190, China
}

Received May 22, 2012; accepted August 2, 2012

\begin{abstract}
In this paper, three kinds of water-soluble fullerene derivatives were synthesized via electrophilic addition reaction and cycloaddition reaction, respectively. The chemical composition characterizations of these derivatives indicated the successful preparation of $\mathrm{C}_{60}(\mathrm{OH})_{x}, \mathrm{C}_{60}\left(\mathrm{C}(\mathrm{COOH})_{2}\right)_{x}$ and $\mathrm{C}_{60}(\mathrm{OH})_{x}\left(\mathrm{NHCH}_{2} \mathrm{COOH}\right)_{y}$ fullerene derivatives. The aggregation and morphology characterizations showed that the three kinds of derivatives had an ideal spherical aggregating structures and excellent dispersibility in water, especially $\mathrm{C}_{60}(\mathrm{OH})_{x}$ and $\mathrm{C}_{60}\left(\mathrm{C}(\mathrm{COOH})_{2}\right)_{x}$. The lubrication performance of the fullerene derivatives acted as lubricant additives were investigated at different concentrations in the range of $0-1 \mathrm{wt} \%$. The results indicated that the addition of polyhydroxyl and carboxylic derivatives could improve the lubrication properties, which led to the reduction of wear to about $40 \%$ at most. It is attributed that the optimized substitutions of fullerene molecules may be of benefit to their distribution properties and lubricating behaviors in water based lubrication.
\end{abstract}

fullerene derivatives, dispersibility, water-based lubrication, wear reduction

Citation: Liu Y H, Liu P X, Che L, et al. Tunable tribological properties in water-based lubrication of water-soluble fullerene derivatives via varying terminal groups. Chin Sci Bull, 2012, 57: 4641-4645, doi: 10.1007/s11434-012-5515-2

The discovery [1] and large scale preparation [2] of fullerene $\mathrm{C}_{60}$ are one of the most important achievements in the 20th century. Since then, much attention has been paid to fullerene $\mathrm{C}_{60}$ for its potential applications in physics, chemistry and material science [3-10].

The lubricating properties of fullerene $\mathrm{C}_{60}[1,11]$ have been predicted because of its unique spherical shape, high load-bearing capacity, strong intramolecular forces, weak intermolecular forces, low surface energy and so on. Some researchers predicate that $\mathrm{C}_{60}$ could be used as microsphere ball lubricant $[12,13]$. It has been found that hexagonal close packed structure of fullerene molecules have obliterated phase transition, and the theoretical study find that fullerene molecules can scroll on the surface of graphite and diamond under low pressure [14]. Therefore, fullerene $\mathrm{C}_{60}$ is regarded as a good solid lubricant.

So far, researches on the friction properties of $\mathrm{C}_{60}$ can be

*Corresponding author (email: liuyuhong@ $@$ tsinghua.edu.cn) classified into two categories. One is solid lubrication system focusing on the $\mathrm{C}_{60}$ films, such as sublimation deposition film [15-17] and Langmuir-Blodgett film [18-21]. In 1993, Bhushan et al. [17] got fullerene thin film using sublimation deposition method on polished silicon and studied its tribological properties under a serial of conditions. All the results showed that the friction coefficient decreased in the presence of fullerene thin film. The author attributed this result to the unique crystal structure and chemical bond of fullerene. Other researchers focused on fullerene LB film found that fullerene LB thin film had higher bearing capacity compared with $\mathrm{C}_{60}$ powder [18]. For instance, the $\mathrm{C}_{60}$ monolayer film formed by evaporation of a $\mathrm{BN}$ crucible on highly oriented pyrolytic graphite (HOPG) exhibited a low frictional force of $2 \mathrm{mN}$ [22]. The other studies are fluid lubrication system using fullerene as lubricating additive [23]. All the results indicated that the friction coefficient was approximately twenty percent lower using $5 \mathrm{wt} \%$ fullerene as lubricating additive comparing to that of the base 
oil without additives. Simultaneously, the width of the wear scar was also become smaller. Moreover, fullerene in petroleum could also decrease the friction coefficient and attrition rate.

Though fullerene can be used in many fields, the nature of its own hampered its wide application as clean and green liquid lubricant. For example, fullerene is only soluble in some toxic non-polar solvents with limited concentration, such as benzene, toluene and carbon disulfide. Therefore, it is necessary to modify the structures and properties of the fullerene molecules in order to make them soluble in water or other cleaned solvents. In comparison to oil lubricants, water-based lubricants, which are environment-friendly, have been widely used in food and textile industry. However, the poor lubricating properties and corrosive resistance capacity restricted the use of water-based lubricants. Hence, much work has been dedicated to research in this area. Nowadays, carboxylic acid and its corresponding salt are widely used as water-based lubricant additives. Chemical modification and molecular design have proved to be a useful way to make fullerene a good lubricant additive in water. Guan's group [24-26] have prepared a series of fullerene copolymers and find that the tribological properties of the base stock have been improved with the friction coefficient decreasing and the load-carrying capacity increasing by using these fullerene derivatives as lubrication additives. Although, much work has been done in modification of the fullerene molecules, no regular results were obtained. Therefore, three kinds of fullerene derivatives modified by polyhydroxyl, carboxyl and combined groups are prepared. The tribological properties of these three fullerene derivatives using as lubrication additive are investigated systematically so as to find out which kind of derivative is more suitable for water-based lubrication additive.

\section{Experimental}

\subsection{Synthesis and characterization of fullerene derivatives}

Three kinds of novel water-soluble fullerene derivatives $\mathrm{C}_{60}$ polyhydroxyl derivative, $\mathrm{C}_{60}$ carboxylic derivative and $\mathrm{C}_{60}$ derivative containing carboxyl and hydroxyl groups were prepared via electrophilic addition reaction and cycloaddition reaction. The compositions of the three $\mathrm{C}_{60}$ derivatives were characterized by FTIR, UV, XPS and MALDI-TOF MS. According to the experimental data, the molecular formula of the three fullerene derivatives was identified as $\mathrm{C}_{60} \mathrm{O}_{7}(\mathrm{OH})_{223}(\mathbf{1}), \mathrm{C}_{60}\left(\mathrm{C}(\mathrm{COOH})_{2}\right)_{5}(\mathbf{2})$, and $\mathrm{C}_{60}(\mathrm{OH})_{\sim 6^{-}}$ $\left(\mathrm{NHCH}_{2} \mathrm{COOH}\right)_{\sim 33}(3)$, respectively. All the detail information could be found in Supporting Information.

\subsection{Aggregation and morphology study of the three fullerene derivatives}

Morphology and size distribution of the derivatives in water were measured using transmission electron microscope (TEM) (H-7650B, Hitachi) and multimode atomic force microscopy (AFM) (nanoIIIA, Veeco) using an tappingmode cantilever holder under ambient condition. Commercial silicon cantilevers with resonant frequencies $\sim 317 \mathrm{kHz}$ and spring constant $\sim 42 \mathrm{~N} / \mathrm{m}$ were obtained from Veeco.

\subsection{Measurement of tribology properties}

The corresponding lubrication properties were investigated using universal micro-tribotester (UMT-2, CETR) and Micro-XAM 3D profiler, which were in consistent with the morphology and dispersibility results shown in TEM and AFM images. As pure water had poor lubricity and corrosive property, a triethanolamine aqueous solution (2 wt $\%$ ) was widely used as the base stock in metal-working fluids. The fullerene derivatives prepared above were used as lubricant additives in base solution (triethanolamine $2 \mathrm{wt} \%$ and nonylphenol ethoxylates $0.5 \mathrm{wt} \%$ ). The tribological measurement was carried out using $\mathrm{Si}_{3} \mathrm{~N}_{4}$ ball (Diameter: $4 \mathrm{~mm}$; Roughness $\mathrm{Ra}$ is about $5 \mathrm{~nm}$ ) and silicon wafer as friction pairs. The normal load was $250 \mathrm{~g}$ and the sliding speed was $10 \mathrm{~mm} / \mathrm{s}$. The independent experiments were repeated at least 3 times, and comparable results were presented below. 3-D optical profiling of the wear scar was achieved with a Micro-XAM 3D profiler (ADE Phase Shift).

\section{Results and discussions}

The morphologies of the three kinds of fullerene derivatives were investigated from the TEM images as shown in Figure 1. It can be seen that the derivatives present a spherical appearance in water and aggregated to some extent, the diameters of the fullerene derivatives aggregations 1-3 measured in TEM are $40-70 \mathrm{~nm}, 30-60 \mathrm{~nm}$ and $30-80 \mathrm{~nm}$, respectively. It can be seen from the TEM images that the dispersion of carboxylic derivative is better than the other two kinds of fullerene derivatives. This phenomenon may be ascribed to the different structures of the fullerene derivatives, such as the quantity of hydroxyl and carboxylic groups. Fullerene polyhydroxyl derivative contains about twenty three hydroxyl groups in each fullerene molecule (eq. (S1)) and fullerene derivative containing hydroxyl and carboxyl groups have ca. six hydroxyl groups and thirty three carboxyl groups in each molecule (eq. (S3)), which greatly increase the intermolecular interaction of fullerene derivatives rather than the interaction between the fullerene derivative molecules and solvent, resulting in the aggregation of fullerene molecules. In addition, lots of substituent groups may destroy the spherical structure of fullerene molecules. Therefore, it may be one of the most important strategies to improve the dispersion of the fullerene derivatives by varying the kind and amount of substituents, leading to the controllable interaction between the fullerene derivative molecules 


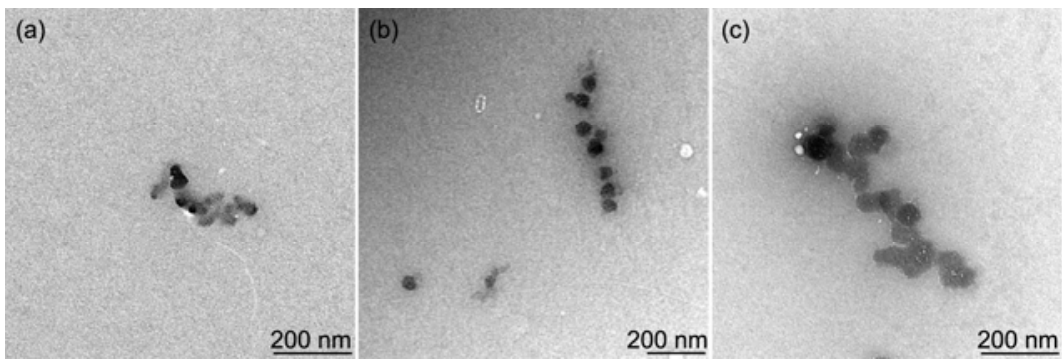

Figure 1 TEM images of water soluble fullerene derivatives. (a) Polyhydroxyl derivative 1; (b) carboxylic derivative 2; (c) derivative containing hydroxyl and carboxyl groups 3 .

and solvent.

Atomic force microscopy (AFM) study was carried out to probe the surface morphology and particle size of the fullerene derivatives. It can be seen from the images that $\mathrm{C}_{60}$ derivative 2 is evenly distributed and some of the derivative $\mathbf{1}$ and $\mathbf{3}$ gathered together to form a big cluster. The particle heights of polyhydroxyl derivative, carboxylic derivative and derivative containing hydroxyl and carboxyl groups is ca. 71, 2 and $61 \mathrm{~nm}$ respectively from the results of the section measurements, as shown in Figure 2.

From the results of AFM images, the carboxylic derivative particle size is smaller and evenly distributed than the other two kinds of fullerene derivatives. This result is corresponding to that of the TEM (Figure 1). The self-aggregation of sample $\mathbf{1}$ and $\mathbf{3}$ should be attributed to the domination of the hydrogen-bonding interactions existed among the plenty of hydroxyl and carboxyl groups [27], while there are only five carboxyl groups for each sample 2 molecule, resulting in the weak effects of molecular interactions and the particle uniform distribution. As a solid lubrication additive, the particle size of fullerene derivatives play an important role in their lubrication behaviors; the fullerene derivative molecules with the optimizing dispersibility may decrease the friction coefficient and increase the resistance of wear.

For characterizing the lubrication properties and the antiwear abilities of the fullerene derivatives synthesized above, the Universal Micro-tribotester (UMT) and Micro-XAM 3D Profiler were used to investigate the friction coefficients and wear scars under the condition of the normal load $250 \mathrm{~g}$ and sliding speed $10 \mathrm{~mm} / \mathrm{s}$. The friction coefficient (COF) measurements of the lubricants with the additives of fullerene polyhydroxyl derivative, carboxyl derivative and derivative containing hydroxyl and carboxyl groups were carried out and the results were given in Figure 3(a). It can be seen that as the concentration of polyhydroxyl derivative increases, the COF exhibited a V-shaped pattern, that is, the friction coefficient decreases firstly and then increases. Although the COF does not follow a regular rule, the COF reach a minimum when the concentration of added fullerene derivative is about $0.6 \mathrm{wt} \%$. The COF results of carboxyl derivative indicated that as the concentration of carboxylic derivative increases, the COF decrease firstly and then increase as the derivative concentration lower than $0.6 \mathrm{wt} \%$. When the concentration of derivative reaches $0.4 \mathrm{wt} \%$, the $\mathrm{COF}$ is minimum and when the derivative content is about $0.6 \mathrm{wt} \%$, the COF is maximum. On the other hand, the COF decrease as the derivative content increase when derivative concentration is higher than $0.6 \mathrm{wt} \%$. The tribology property of derivative containing hydroxyl and carboxyl groups illustrate that as the concentration of derivative increases, the COF increase compared to that of the base stock. There are competitions interaction between $\mathrm{OH} \cdots \mathrm{OH}, \mathrm{COOH} \cdots \mathrm{COOH}$ and $\mathrm{OH} \cdots \mathrm{COOH}$. At different concentration, the interactions between these groups are different, so the enhanced tribological properties of $\mathrm{C}_{60}$ polyhydroxyl derivative and carboxyl derivative at certain concentration may be improved by combination of interaction strength between $\mathrm{OH} \cdots \mathrm{OH}$ and $\mathrm{COOH} \cdots \mathrm{COOH}$ and $\mathrm{OH} \cdots \mathrm{COOH}$ [28]. According to the AFM and TEM results we conclude above, carboxyl derivatives have small particle size and evenly distributed in base stock. It can be seen clearly in the AFM image that the surface coverage of carboxyl derivative is higher than those of
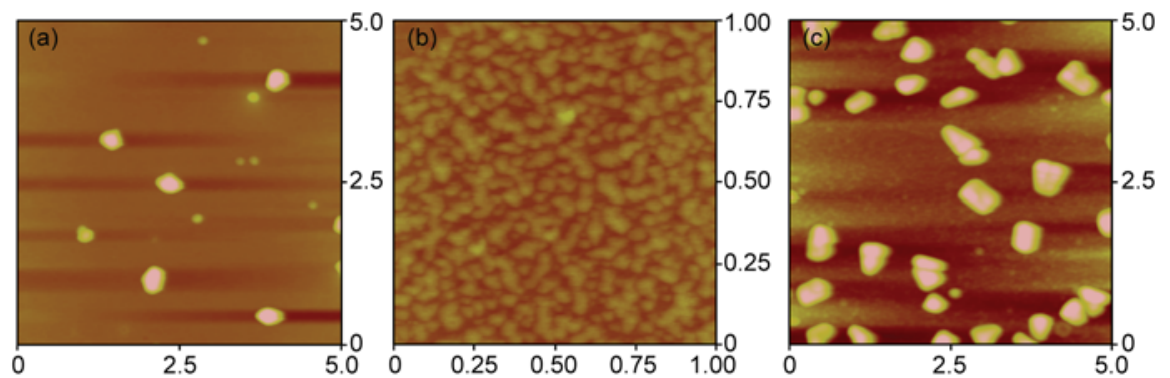

Figure 2 AFM images of fullerene derivatives in water. (a) Polyhydroxyl derivative (scan size: $5 \mu \mathrm{m} \times 5 \mu \mathrm{m}$, height scale: $100 \mathrm{~nm}$ ); (b) carboxyl derivative (scan size: $1 \mu \mathrm{m} \times 1 \mu \mathrm{m}$, height scale: $20 \mathrm{~nm}$ ); (c) derivative containing hydroxyl and carboxyl groups (scan size: $5 \mu \mathrm{m} \times 5 \mu \mathrm{m}$, height scale: $100 \mathrm{~nm}$ ). 
other derivatives. Therefore, the tribological properties are improved greatly [29] at a lower derivative concentration, for example $0.4 \mathrm{wt} \%$.

The wear scar size data of fullerene polyhydroxyl derivative, carboxyl derivative and derivative containing hydroxyl and carboxyl groups are given in Figure 3(b)-(d). For fullerene polyhydroxyl derivative, it can be indicated from Figure 3(b) that the depth and the width of the wear scar both come to a minimum when the concentration of fullerene polyhydroxyl derivative reaches $0.6 \mathrm{wt} \%$, which is consistent with the results of COF. These results indeed indicate that the addition of fullerene polyhydroxyl derivative with the concentration of $0.6 \mathrm{wt} \%$ has the better lubricating property. By comparison with the wear scars of the base stock, it can be seen clearly that the wear scar with $0.6 \mathrm{wt} \%$ of fullerene polyhydroxyl derivative is much smaller than that of the base stock. Therefore, the addition of polyhydroxyl derivative can improve the lubricating property, resulting in the wear reduction down to $40 \%$.

The wear scar size data carboxyl derivative are illustrated in Figure 3(c), the results indicate that the depth and the width of the wear scar both come to a minimum only when the derivative content reaches $0.2 \mathrm{wt} \%$. With other derivative concentration, the depth and the width of the wear scars are larger than that of the base stock. By comparisons with the wear scars, it can be seen that the wear scar of the solution containing $0.2 \mathrm{wt} \%$ derivative is much smaller than that of the base stock. There are more smooth wear scars than that of base solution. Therefore, the presence of carboxylic derivative when its concentration is $0.2 \mathrm{wt} \%$ can enhance the wear resistance of the base stock because of the lower friction coefficient, which is correlative with the distribution
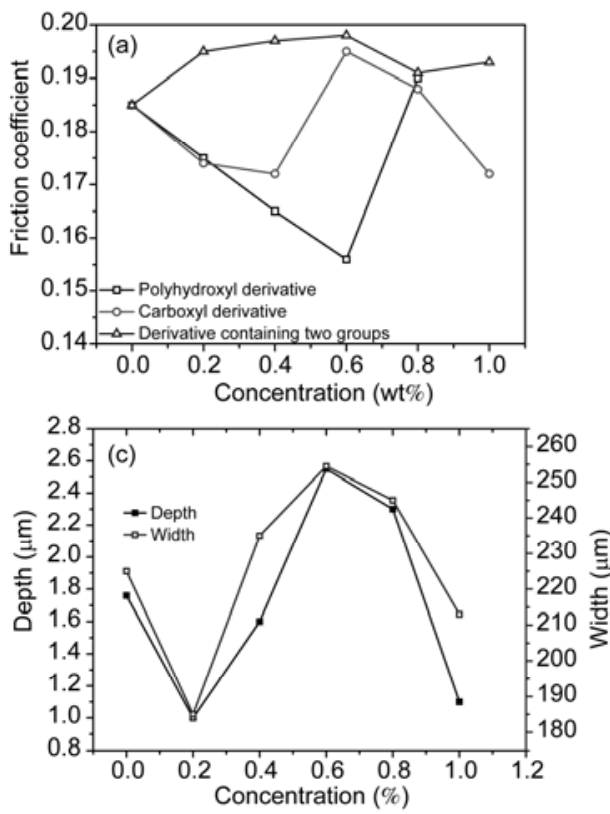

properties in water base stock. And the wear scar data of fullerene derivative containing hydroxyl and carboxyl groups is shown in Figure 3(d). The wear scar size increases as the concentration of derivative increases to $0.6 \mathrm{wt} \%$ by the comparison of the wear scars, it is obvious that the wear scar of the solution containing $1.0 \mathrm{wt} \%$ is larger than that of the base stock, and more particles appear than that of base solution. That is to say, the addition of derivative containing hydroxyl and carboxyl groups to the base stock could have no significant improvement to the lubricating property of the solution under the experimental conditions. This may be related to the self-aggregation of molecular particles driven mainly by the hydrogen-bonding interactions between hydroxyl and carboxyl groups.

In summary, the addition of $\mathrm{C}_{60}$ polyhydroxyl derivative and $\mathrm{C}_{60}$ carboxylic derivative can improve the lubricating property and the wear resistance ability of the base stock when their concentrations are about $0.6 \mathrm{wt} \%$ and $0.2 \mathrm{wt} \%$ respectively. However, $\mathrm{C}_{60}$ derivative containing hydroxyl and carboxyl groups has no significant influence on the base stock under our experiment conditions. The results showed that the molecular interaction (such as hydrogen-bonding and dipole interactions) and the interactions between the molecular particles and the solvent have significant impact on the molecular aggregation morphologies and distribution properties in water solution, which also influence the lubrication properties.

\section{Conclusions}

Three kinds of water-soluble fullerene derivatives $\mathrm{C}_{60}(\mathrm{OH})_{x}$,
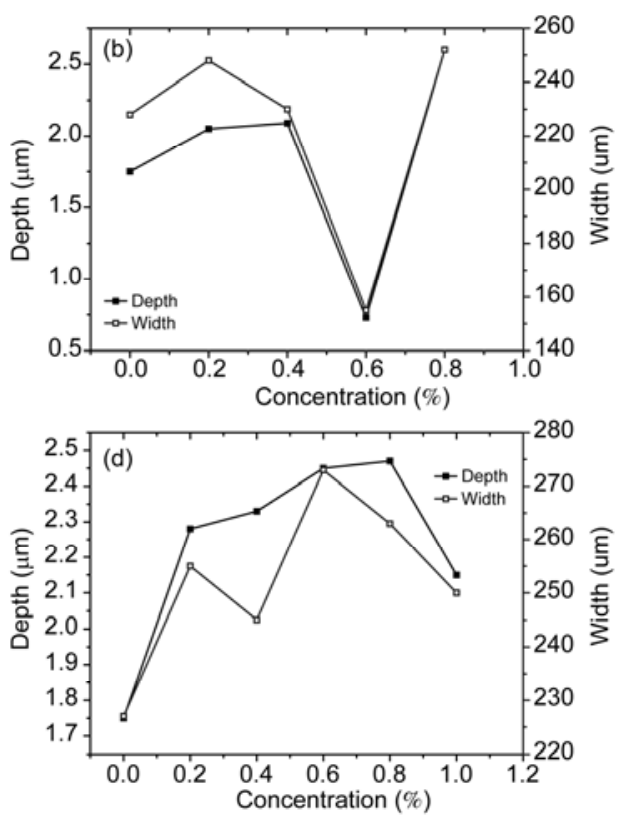

Figure 3 Friction coefficient versus concentration of fullerene polyhydroxyl derivative, carboxyl derivative and derivative containing hydroxyl and carboxyl groups (a), wear scar diameter of fullerene polyhydroxyl derivative $(0.6 \mathrm{wt} \%)(\mathrm{b})$, carboxyl derivative $(0.2 \mathrm{wt} \%)$ (c), derivative containing hydroxyl and carboxyl groups $(1.0 \mathrm{wt} \%)(\mathrm{d})$. 
$\mathrm{C}_{60}\left(\mathrm{C}(\mathrm{COOH})_{2}\right)_{x}$ and $\mathrm{C}_{60}(\mathrm{OH})_{x}\left(\mathrm{NHCH}_{2} \mathrm{COOH}\right)_{y}$ are successfully synthesized. The solubility and the dispersity of $\mathrm{C}_{60}$ were improved significantly by grafting water-soluble functional groups according to the results of their morphology investigations by TEM and AFM, especially the carboxylic derivatives. All the tribological experimental results show that the $\mathrm{C}_{60}$ polyhydroxyl derivative and $\mathrm{C}_{60}$ carboxylic derivative could prominently improve the lubricating properties and surface wear resistant property acted as lubricant additives especially at the concentration of $0.6 \mathrm{wt} \%$ and $0.2 \mathrm{wt} \%$ respectively, in which the wear of surface decreased to $40 \%$ at most. The investigations indicated that there may be some potential strategies to control the molecular aggregation and distribution properties of the $\mathrm{C}_{60}$ derivatives in water-based lubricating condition by the designable molecular modification with the different substituent groups and their quantity, which would have great influence on the molecular interactions, resulting in the enhancement of lubrication properties.

This work was supported by the National Natural Science Foundation of China (50805086), Tsinghua Universiey Initiative Scientific Research Program (201210880) and the Foundation for Innovative Research Groups of the National Natural Science Foundation of China (51021064, 21121063).

1 Kroto H W, Heath J R, Obrien S C, et al. $\mathrm{C}_{60}$ : Buckminsterfullerene. Nature, 1985, 318: 162-164

2 Kratschmer W, Lamb L D, Fostiropoulos K, et al. Solid C 60 : A new form of carbon. Nature, 1990, 347: 354-358

3 Matsubayashi K, Kokubo K, Tategaki H, et al. One-step synthesis of water-soluble fullerenols bearing nitrogen-containing substituents. Fuller Nanotub Carbon Nanostruct, 2009, 17: 440-456

4 Zhang G, Liu Y, Liang D H, et al. Facile synthesis of isomerically pure fullerenols and formation of spherical aggregates from $\mathrm{C}_{60}(\mathrm{OH})_{8}$. Angew Chem, 2010, 49: 5293-5295

5 Otero G, Biddau G, Sánchez-Sánchez1 C, et al. Fullerenes from aromatic precursors by surface-catalysed cyclodehydrogenation. Nature, 2008, 454: 865-868

6 Pieta P, Grodzka E, Winkler K, et al. Conductive, capacitive, and viscoelastic properties of a new composite of the $\mathrm{C}_{60}-\mathrm{Pd}$ conducting polymer and single-wall carbon nanotubes. J Phys Chem B, 2009, 113: 6682-6691

7 Takaya Y, Tachika H, Hayashi T, et al. Performance of water-soluble fullerenol as novel functional molecular abrasive grain for polishing nanosurfaces. CIRP Ann-Manuf Techn, 2009, 58: 495-498

8 Wang C R, Kai T, Tomiyama T, et al. Materials science: $\mathrm{C}_{66}$ fullerene encaging a scandium dimer. Nature, 2000, 408: 426-427

9 Deibel C, Dyakonov V. Polymer-fullerene bulk heterojunction solar cells. Rep Prog Phys, 2010, 73: 096401

10 Ma X, Wigington B, Bouchard D. Fullerene $\mathrm{C}_{60}$ : Surface energy and interfacial interactions in aqueous systems. Langmuir, 2010, 26: 11886-11893

11 Feng B. Relationship between the structure of $\mathrm{C}_{60}$ and its lubricity: A review. Lubr Sci, 1997, 9: 181-193

12 Blau P J, Haberliu C E. An investigation of the microfrictional behavior of $\mathrm{C}_{60}$ particle layers on aluminum. Thin Solid Films, 1992, 219: $129-134$

13 Gupta B K, Bhushan B, Capp C, et al. Materials characterization and effect of purity and ion implantation on the friction and wear of sublimed fullerene films. J Mater Res, 1994, 9: 2823-2838

14 Billups W E, Ciufolini M A, eds. Buckminsterfullerenes. New York: Wiley-VCH, 1993. 125-184

15 Hebard A F, Haddon R C, Flming R M, et al. Deposition and characterization of fullerene films. Appl Phys Lett, 1991, 59: 2109-2111

16 Thundat T, Warmack R J, Ding D, et al. Atomic force microscope investigation of $\mathrm{C}_{60}$ adsorbed on silicon and mica. Appl Phys Lett, 1993, 63: 891-893

17 Bhushan B, Gupta B K. Fullerene $\left(\mathrm{C}_{60}\right)$ films for solid lubrication. Tribol Trans, 1993, 36: 573-580

18 Xue Q J, Zhang J. Friction and wear mechanism of $\mathrm{C}_{60} /$ static-acid Langmuir-Blodgett films. Tribol Int, 1995, 28: 287-291

19 Shi B, Lu X C, Zou R, et al. Observation of the topography and friction property of macromolecular thin films at the nanometer scale. Wear, 2001, 251: 1177-1182

20 Ren S L, Yang S G, Zhao Y P. Preparation and tribological studies of $\mathrm{C}_{60}$ thin film chemisorbed on a functional polymer surface. Langmuir, 2004, 20: 3601-3605

21 Zhang P Y, Lu J J, Xue Q J, et al. Microfrictional behavior of $\mathrm{C}_{60}$ particles in different $\mathrm{C}_{60} \mathrm{LB}$ films studied by AFM/FFM. Langmuir, 2001, 17: 2143-2145

22 Okita S, Matsumuro A, Miura K. Tribological properties of a $\mathrm{C}_{60}$ monolayer film. Thin Solid Films, 2003, 443: 66-70

23 Gupta B K, Bhushan B. Fullerene particles as an additive to liquid lubricants and greases for low friction and wear. Lubr Eng, 1994, 50: 524-528

24 Lei H, Guan W C, Luo J B. Tribological behavior of water-soluble fullerene-methacrylic acid copolymer (in Chinese). J Tsinghua Univ (Sci \& Tech), 2002, 42: 76-79

25 Lei H, Guan W C. Tribological behavior of fullerene-vinyl pyrrlidone copolymer nanoball (in Chinese). J Huazhong Univ Sci Tech, 2000, 28: $98-101$

26 Lei H, Guan W C, Liao D X. Experimental study on tribological properties of fullerene copolymer nanoball. Chin J Mech Eng, 2000, 13: 201-205

27 Shu C Y, Zhang E Y, Xiang J F, et al. Aggregation studies of the watersoluble gadofullerene magnetic resonance imaging contrast agent: $\left[\mathrm{Gd} @ \mathrm{C}_{82} \mathrm{O}_{6}(\mathrm{OH})_{16}\left(\mathrm{NHCH}_{2} \mathrm{CH}_{2} \mathrm{COOH}\right)_{8}\right]_{x}$. J Phys Chem B, 2006, 110: 15597-15601

28 Xu S L, Yin S X, Liang H P, et al. Identification of the preferentialbonding effect of disubstituted alkane derivatives using scanning tunneling microscopy. J Phys Chem B, 2004, 108: 620-624

29 Xu S L, Kang S Z, Deng G J, et al. Nanofrictional properties of dendron Langmuir-Blodgett films. Chem Lett, 2003, 32: 290-291

Open Access This article is distributed under the terms of the Creative Commons Attribution License which permits any use, distribution, and reproduction in any medium, provided the original author(s) and source are credited.

\section{Supporting Information}

1 Preparation of $\mathrm{C}_{60}$ fullerene derivatives

2 Characterization of $\mathrm{C}_{60}$ fullerene derivatives

The supporting information is available online at csb.scichina.com and www.springerlink.com. The supporting materials are published as submitted, without typesetting or editing. The responsibility for scientific accuracy and content remains entirely with the authors. 